\title{
Quality Data Acquisition and Application in Electronic Assembly Based on Manufacturing Internet of Things
}

\author{
Xiaorang Feng ${ }^{\text {a }}$, Xujie $\mathrm{Hu}^{\text {b }}$ \\ China Aerospace Architectural Design \& Research Co., Ltd, Beijing 100071, China. \\ afxrheiman@126.com, bhuxujielukcy@163.com
}

\begin{abstract}
According to the quality management requirements of acquisition and tracing data such as real-time status of parts, manufacturing data during electronic assembly process, a technical architecture of data based on manufacturing internet of things enabled environment was constructed. Based on this architecture, a quality data acquisition and application method was put forward and the application model was provided. The data acquisition and application prototype system was developed and its physical architecture, functional module was introduced in detail. An electronic assembly workshop was taken as the application object to demonstrate proposed technology. The system can acquire quality data real-timely, analyze and feedback data accurately. Both the quality of products and quality management level was improved.
\end{abstract}

Keywords: Manufacturing internet of things; Quality management; Data acquisition; Data tracing; Electronic assembly.

\section{Introduction}

Manufacturing internet of things is the application and development of Internet of things in manufacturing domain. It uses new information technology such as radio frequency identification (RFID), sensors, to connect manufacturing resources with internet. The "things-things" connection can be achieved by real-time information acquisition, reliable information transformation, and intelligent information procession [1,2]. Manufacturing internet of things supports intelligent identification, location, tracing, monitoring, which provide manufacturing control and management with more convenient and ubiquitous information identification and transformation environment. It improves the intelligence of the factory and manufacturing process [3, 4].

Aiming at some shortages in traditional quality management of electronic assembly process, a technical architecture of data based on manufacturing internet of things enabled environment was constructed in this paper. Based on this architecture, a quality data acquisition and application method was put forward and the application model was provided. The method proposed aimed to achieve effective data acquisition and feedback, in time decision, to improve production quality, to guarantee production time, and to minimize production cost.

\section{Technical Architecture of Data Based on Manufacturing Internet of Things}

The technical architecture of data in workshop is based on production process information such as materials, equipment, workers, environment, manufacturing execution, and products. The internet of things is used to connect these information to enterprise's information manage system by providing data and supporting data collaborative using.

The architecture consists of automatic control layer, manufacturing internet layer, and manufacturing executive layer, as is shown in figure 1. The core of manufacturing internet of things is a large number of sensors network and objective name service (ONS) platform. It was applied to manage and use manufacturing resource data and product data collaboratively. The ONS is an automatic network service system which analyses EPC code to store relative data service address information [5]. The address information indicates the server to RFID, provides information interchange service to outside, and constitutes manufacturing internet architecture by connecting with ONS. Based on this architecture, information system and manufacturing executive system (MES) can use manufacturing information and production data through manufacturing internet layer instead of exchange data directly with equipment, monitoring devices, and so on. 


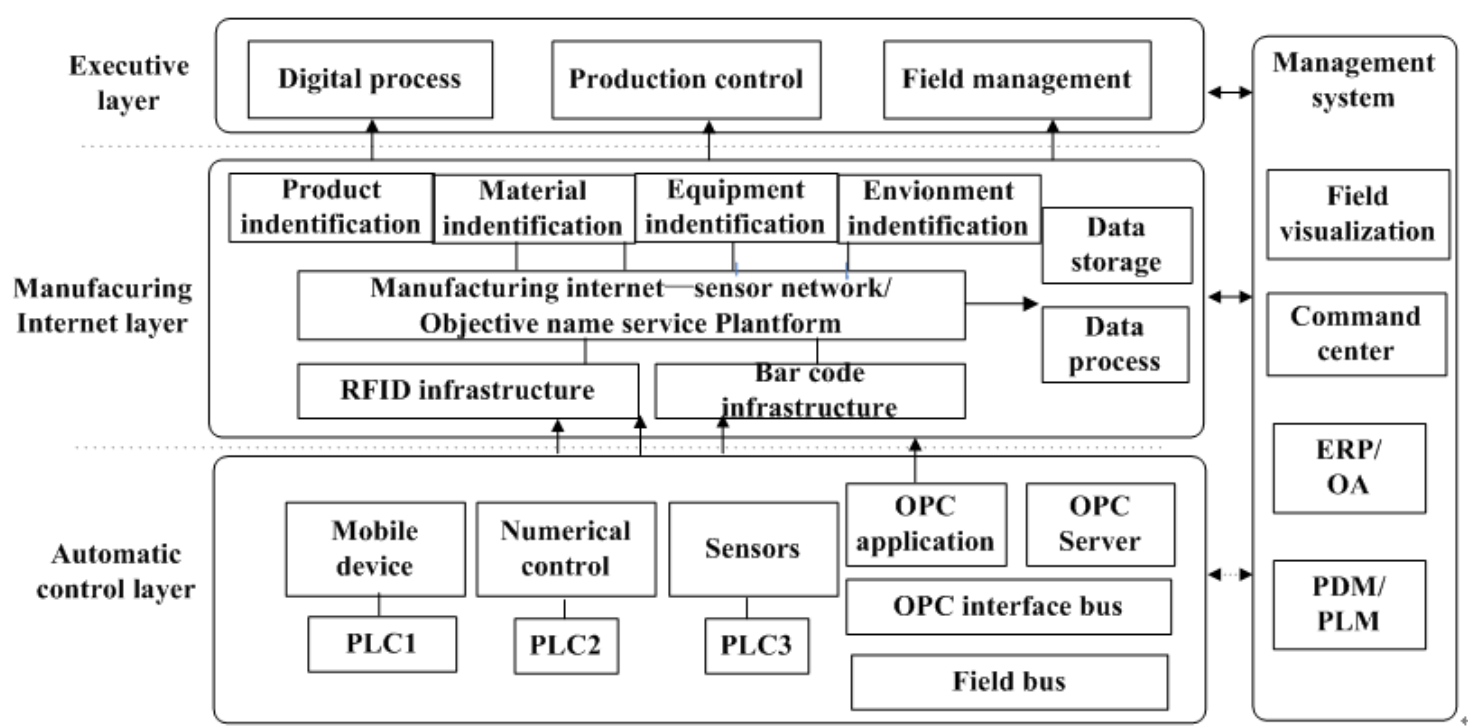

Fig. 1 Technical Architecture of Data Based on Manufacturing Internet of Things

\section{Application Model of Electronic Assembly Quality Data Acquisition}

\subsection{Data Requirement Analysis and Data Classification}

The workflow of electronic assembly concludes SMT line, assembly, test process which interlinks to affect products quality. Nowadays, there are several shortages in electronic assembly procedure such as low passing rate in SMT, rosin joint, lack of weld, wrong weld, high error rate, unstable and unreliable signal source in fixture tools testing. Furthermore, in quality management, data summary and classification largely relay on manual work. Most information cannot be transferred to electronic and digital management, which result in difficult query, inaccurate acquisition, deviation in analysis, and difficulties in real-timely feedback. Therefore, in production pro-cess, management system should record and analyses relevant quality data of material, part batch, semi-finished and finished products to support tracing back of quality problem. Test standards, rules, and undesirable problem coding should be constructed to support SPC analysis, undesirable problem rate and cause analysis report, and KPI analysis.

According to above requirements, the objective data of quality data acquisition mainly conclude fixed property data and process property data. (1) Fixed property data do not change with pro-duction procedure. For example, equipment code, workplace code, workers code, material code, and batch code [6]. (2) Process property data often change according to production procedure. For example, working procedure, logistics, start time of a process, finish time of a process, equipment status.

\subsection{Application Model of Quality Data Acquisition}

The application model is shown in Figure 2. It concludes three parts.

The bottom is basic support layer. It provides quality analysis with basic system and data management function. The function consists of product data, production procedure data, unqualified problem code, quality analysis module, quality limit and early warning identification, and maintenance management.

The middle part is acquisition executive layer. According to electronic assembly process schedule, quality data acquisition points are settled in SMT, assembly, test, package procedure using RFID label, bar-code recognition, and so on. This method can collect data relative to workplace and equipment status, material supplement, random inspection, unqualified problem, and maintenance records. The information can be feedback to production management system and guide production execution. 
The top is data application layer. Based on quality data, SPC analysis which concludes material report, IQC test report, unqualified rate, unqualified problem analysis report, quality KPI statistics report, data application can realize material tracing, procedure tracing and package tracing.

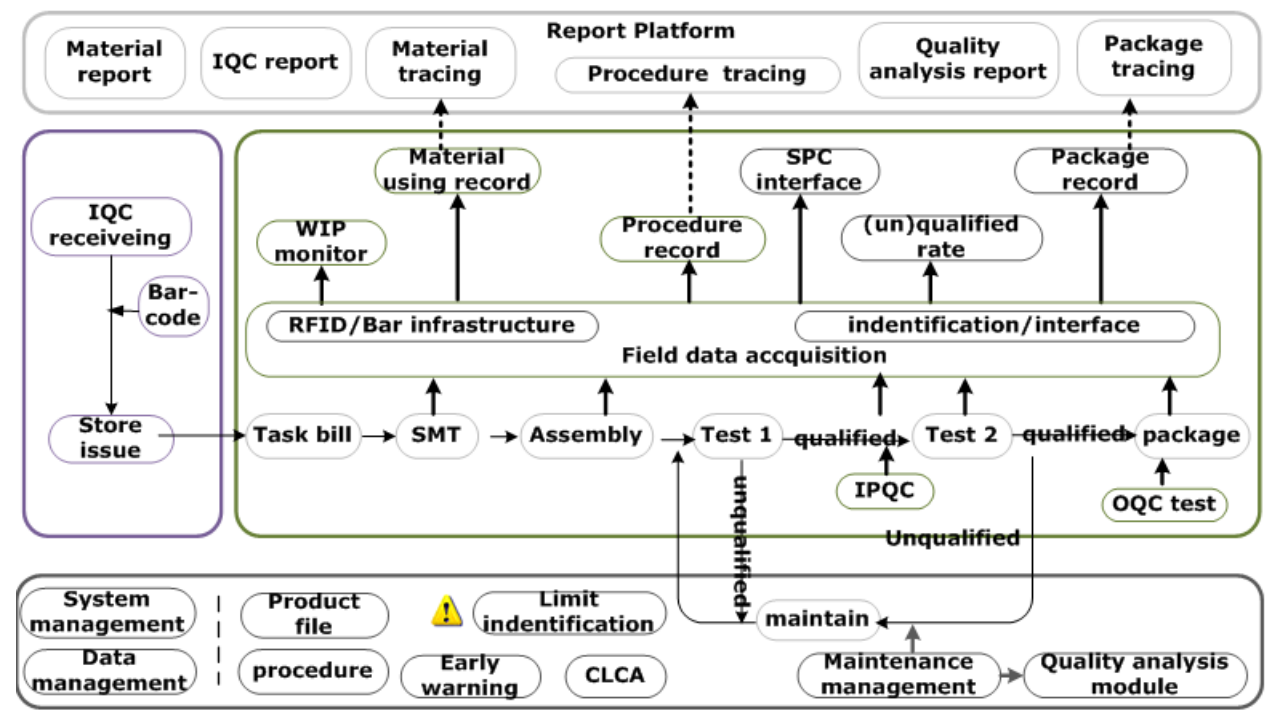

Fig. 2 Application Model of Electronic Assembly Quality Data Acquisition

\section{Quality Data Acquisition and Application System Design}

\subsection{Physical Framework}

The physical framework of quality data acquisition and application system is as figure 3 . The system realizes the interaction of workplace, hardware equipment, control system based on industrial Ethernet. It transmits data of each spot to data acquisition and application servers based on the network, and accomplishes quality monitoring, early-warning, and analysis through data application. The system can be deployed in workshop local area network as an independent system. The local area network connects with factory main network through switches and establishes communication link to support data transmission and interchanging between MES server, CAPP/PDM server, database server and quality acquisition system.

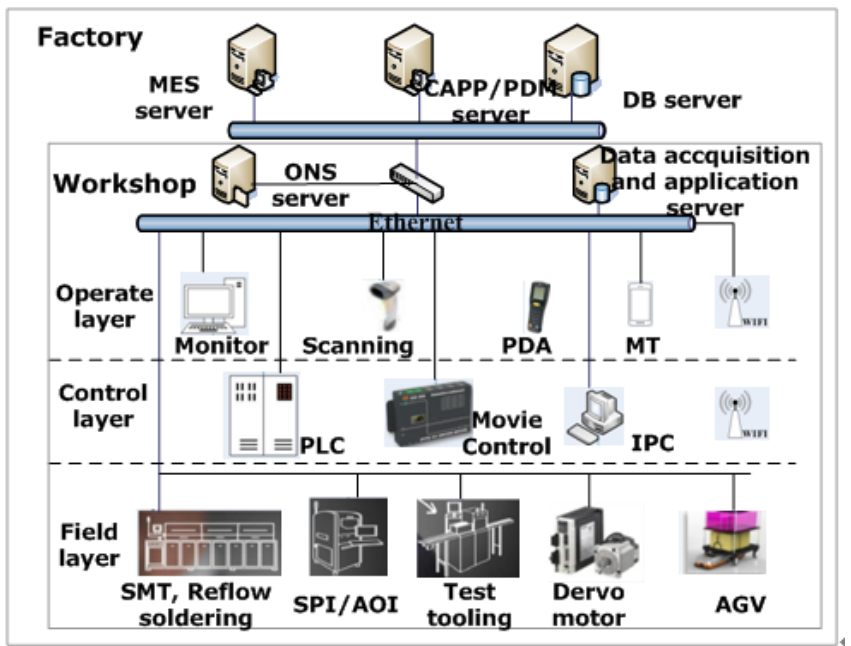

Fig. 3 Physical Framework of the System

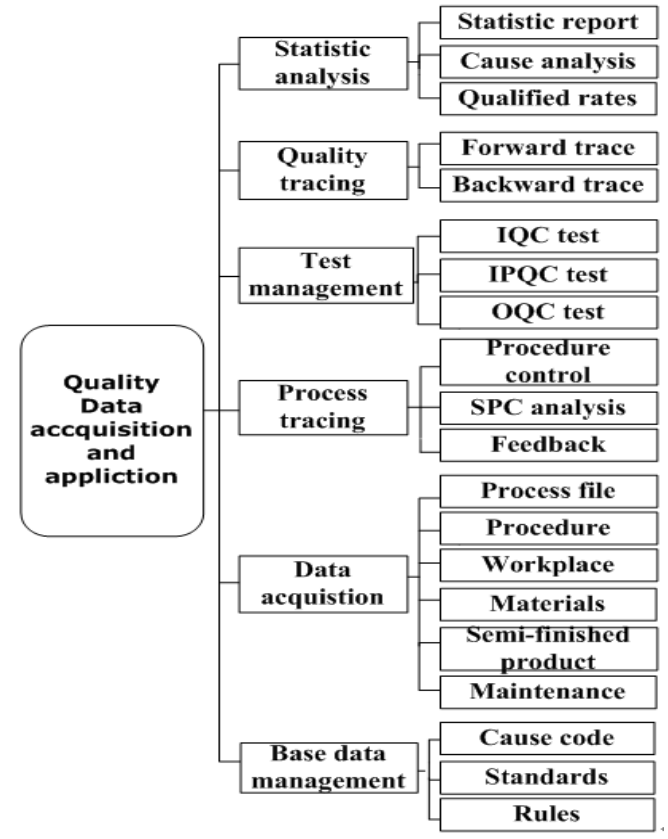

Fig. 4 The Function Module of the System 


\subsection{System Function}

The quality data acquisition and application system's should manage quality relative data such as process, materials and semi-finished products, equipment status, and inquire, backtrack data through interface or mobile terminal. The detail of functions is shown in figure 4.

\section{System Application}

Based on an electronic assembly workshop, a prototype system is developed using Visual C\#.NET, Oracle $11 \mathrm{~g}$. RFID and two-dimension code are taken into application to add the number of quality check spots and locate the unqualified problem. It provides database to adjust production process, equipment, and parameter, and to improve the qualified product rate.

The system supports automatic SPC analysis. Unqualified rate in random inspection, damage rate, direct qualified rate, and so on, can be classified according to certain period, product category. The analysis report can be built automatically. The system also supports product tracing and material tracing. If unqualified material is checked out, the system can trace which product using the unqualified material. On the other hand, if unqualified product is checked out, the supplier and the batch number of the material it uses can be identified.

\section{Conclusion}

Aiming at needs to product's real-time status, pro-duction procedure data acquisition and tracing in quality management of electronic assembly, a technical architecture of data based on manufacturing internet of things enabled environment was constructed. Based on this architecture, a quality data acquisition and application method was put forward and the application model was provided. The data acquisition and application prototype system was developed and its physical architecture, logical architecture, and functional module was introduced in detail. An electronic assembly workshop was taken as an example to demonstrate the proposed technology. The system can acquire quality data real-timely, analyze and feedback data accurately. Both the quality of products and quality management level was improved.

\section{References}

[1]. Brewer A., Sloan N., Landers T. L. Intelligent tracking in manufacturing. Journal of Intelligent Manufacturing.Vol.10 (1999), No. 3-4, p.245-250.

[2]. Jiang X. Y., Wang S. J., Zhao K., et al. Intelligent procedure quality control system oriented network-based manufacturing. Journal of Mechanical Engineering. Vol. 46 (2010), No. 4, p.186194.

[3]. Zhong R. Y., Dai Q. Y., Qu T., et al. RFID-enabled real-time manufacturing execution system for mass-customization production. Robotics and Computer-Integrated Manufacturing. Vol. 29 (2013), No.2 , p. 283-292.

[4]. Chen J. C., Cheng C. H., Huang P. T. B. Supply chain management with lean production and RFID application: a case study. Expert Systems with Applications. Vol. 4 (2013), No. 9, p. 33893397.

[5]. Hou R. C., Ding X. Q., Tao Y., et al. Internet of manufacturing things and relevant technical architecture. Computer Integrated Manufacturing Systems. Vol. 20 (2014), No.1, p.11-20.

[6]. Nie Z., Leng H., Ye W. H., et al. Development of date collection and management in numerical workshop based on internet of things. Machine Building \& Automation. Vol. 44(2015), No.4, p. 98-101. 